\title{
МОНОПОЛИЗАЦИЯ ИНТЕЛЛЕКТУАЛЬНОГО КАПИТАЛА КАК ДВИЖУЩАЯ СИЛА ЭНДОГЕННОГО РОСТА ЭКОНОМИКИ
}

\author{
(C) 2019 Ларионов Антон Валерьевич \\ Самарский государственный экономический университет \\ 443090, Самара, ул. Советской Армии, 141 \\ E-mail: alarionov@corp.finam.ru
}

В статье проанализировано исследование, получившее Нобелевскую премию по экономике 2018 года, посвященное решению проблемы экономического роста. Отмечено, что эндогенный рост экономики на основе научно-технического прогресса сопровождается развитием процессов монополизации интеллектуального капитала. Взаимное проникновение монополизации и высокой конкуренции рассмотрено как явление, в плоскости бизнеса высокотехнологичных компаний и операционной деятельностью других фирм. Предложена гипотеза: фактор разнообразия идей и технологий дает синергетический эффект общей факторной продуктивности для конечного продукта.

Ключевые слова: интеллектуальный капитал, бизнес-процессы, структурный капитал, монополизация, человеческий капитал, эндогенный рост.

Как отметили в Королевской академии наук, Пол Ромер убедительно показал, как знания могут служить драйвером долгосрочного экономического роста. «Предыдущие макроэкономические исследования подчеркивали, что технологические инновации выступают основным драйвером экономического роста, но не моделировали, как экономические решения и рыночные условия определяют разработку новых технологий. Пол Ромер решил эту проблему, показав, как экономика определяет готовность фирм создавать новые идеи и инновации»,- говорится в релизе.

Ромер предложил теорию, согласно которой технологические инновации и знания являются дополнительным фактором производства, а накопление этих знаний и система их распределения позитивно воздействуют на производительность труда и рост капитала. Эндогенный рост экономики как раз базируется на внутренних факторах инклюзивного свойства - знания, инновации и инвестиции в человеческий капитал [1]. Соответственно, потенциал увеличения темпов роста экономики и поддержания ее долгосрочного развития находится в плоскости поддержки образования, научных исследований и разработок, а государственное воздействие осуществляется через повышение стимулов для внедрения инноваций, создание инновационной экосреды.

Попробуем разобраться в самой Модели, а также исследуем интеллектуальный капитал как составную ее часть, выступающий источником долговременного роста по Ромеру, сквозь призму конкурентной среды. Принято считать, что бурное развитие технологических рынков и инновационных компаний является продуктом свободного предпринимательства и олицетворением совершенной конкуренции, с минимальным участием государства в рыночной экономике. Так ли это?

Модель Ромера (Эндогенный рост), Ключевые тезисы и параметры Модели:

- Источник долгосрочного роста - генерация новых знаний.

- Знания создаются и накапливаются как Капитал.

- Распространение знаний приводит к положительным внешним эффектам (экстерналии), в т.ч. «экономия масштаба на макроуровне».

Основным фактором экономического роста является рост капиталовложений в НИОКР и инвестиции в человеческий капитал, при сохранении классических факторов производства (капитал, труд, земля) [2].

Фундаментальные характеристики экономики:

- Предпочтения потребителей.

- Технологические параметры.

- Институциональные факторы.

При целенаправленной государственной политики это дает толчок к «экономике знаний» и 
ускоряет эндогенные темпы роста экономики.

Человеческий капитал накапливается аналогично физическому, благодаря чему совокупная отдача факторов не уменьшается, что означает долговременный рост экономики на эндогенной основе (определяется внутренними факторами и заданными параметрами модели). В рамках модели Ромера синтезируется долговременный рост экономики и ее фундаментальные характеристики на макроуровне, которые проецируют предпочтения потребителей, технологические параметры, а также институциональные факторы. Благодаря увязке именно этих характеристик с темпами экономического роста удалось обосновать дифференциацию темпов по странам (ранее этого не удавалось сделать) - все дело в различиях фундаментальных характеристик экономики [3]. Иными словами, экономика знаний выступает катализатором эндогенного роста, как ключевая составляющая соответствующей институциональной среды.

Полом Ромером также отмечена зависимость от величины экономики - численности населения и работников (эффект размера экономики), а также различие в регионах или экономиках, связанных эффектом растекания знаний, что позволяет каждой фирме иметь внешний эффект от всего объема капитала и экономики. Разная степень связанности экономик эффектом растекания также объясняет межстрановые различия темпов роста экономик. Например, для регионов Китая или России эта связь и интегрированность в мировой информационный обмен может быть существенно ниже, чем связь между странами Евросоюза, или степень включенности Сингапура в мировой процесс растекания знаний (для эмпирических исследований автором вводится коэффициент степени растекания, распространения знаний).

А как, собственно, создаются новые технологии и запускаются процессы генерации новых знаний в рамках Модели Ромера?

Механизм создания новых технологий (двигатель роста) выглядит следующим образом.

Инновационная сфера деятельности, ко- торая предполагает создание и прикладное применение новых технологий, есть ключевой сектор экономики знаний. Технологические предприниматели руководствуются рыночными стимулами, которые сбалансированы с целенаправленной государственной политикой, их деятельность сопряжена с генерацией технологических знаний, которые и представляют собой новый продукт, предвестник нового рынка, новой потребительской модели. Эти технологические знания определены как товары с особыми свойствами [4]. Такими товарами (рисунок 1) могут пользоваться многие лица, но доступ к ним всегда ограничен с целью защиты самой технологии, где инструментарием может выступать патентное право или специальные технические средства.

Ромер в рамках своей модели инновационного роста (рисунок 2) выделяет три сектора: конечного продукта (1), промежуточного продукта (2) и сектора исследований и разработок (3). Сектор конечного продукта использует спектр технологий, воплощенных в различных видах капитального оборудования.

Сектор промежуточного продукта производит это оборудование, покупая технологические патенты в секторе исследований и разработок.

Сектор (3) исследований и разработок генерирует рост, а промежуточный сектор (2) выполняет роль передаточного звена. Это возможно только благодаря монопольному положению, которое гарантируется производителю промежуточного продукта патентным правом. В результате рост производительности коррелирует с ростом суммарных знаний, имеют соответствующий коэффициент, который характеризует их взаимосвязь.

Производство новых идей дает динамический внешний эффект, который реализуется во времени, причем неограниченно долго. Разработчики новых технологий опираются на полученные ранее знания, то есть «стоят на плечах гигантов». Общая продуктивность для конечного продукта растет с тем же темпом.

РЫНОЧНЫЕ СТИМУЛЫ (государственная политика + фундаментальные характеристики) -> УЧАСТНИКИ (научно-предпринимательская деятельность) -> ТЕХНОЛОГИЧЕСКИЕ ЗНАНИЯ (Продуктивный Результат, товар с особыми свойствами)

Доступ к ТОС лимитирован через а) Патентное право и б) Технические средства

Рис.1. Взаимосвязь рыночных стимулов и технологических знаний 


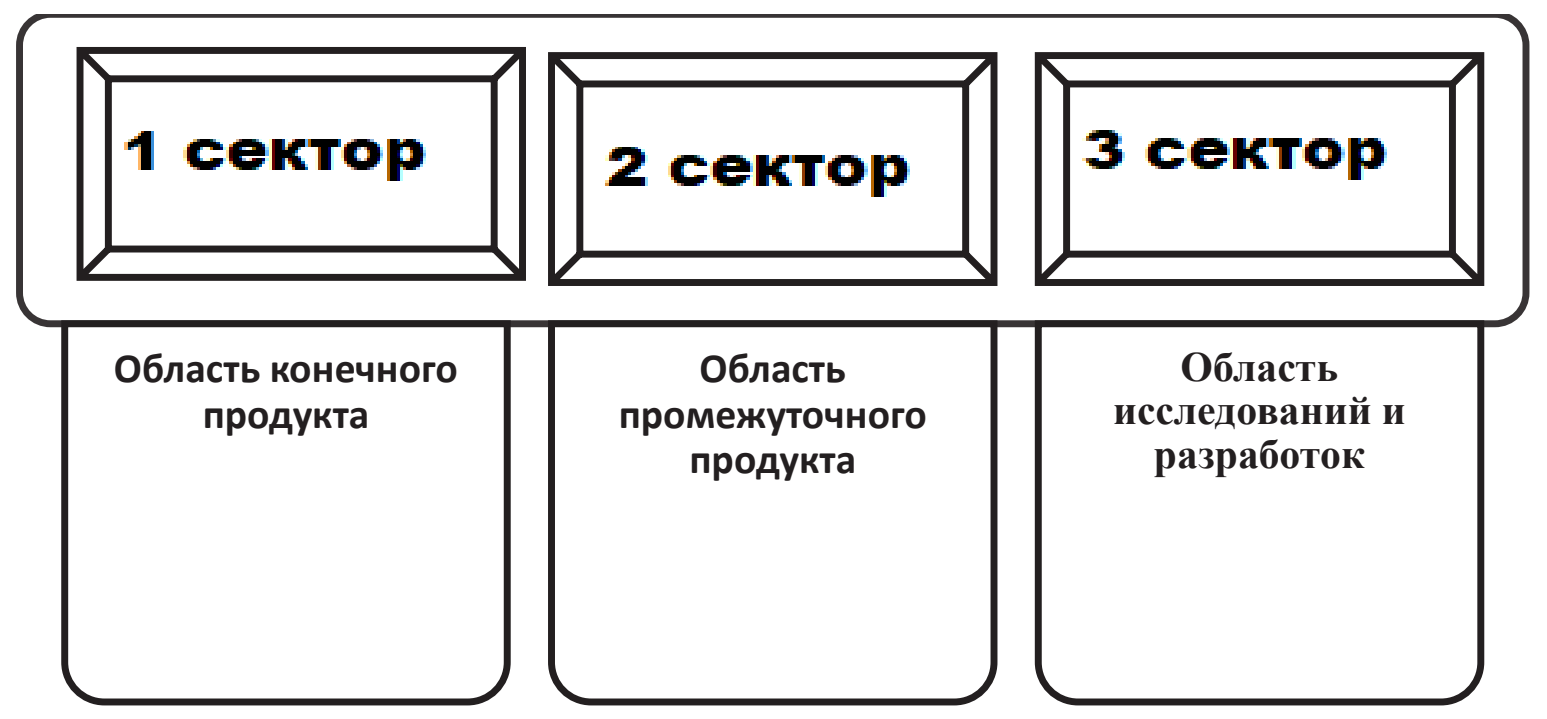

Puc. 2. Модель инновационного роста

Как работают механизмы монополизации интеллектуального капитала?

В рамках Модели П. Ромера отчетливо прослеживаются процессы концентрации, с последующей монополизацией интеллектуального капитала вообще, и новых знаний в частности. Созданная институциональная среда на макроуровне - как целенаправленная государственная политика - стимулирует технологическое предпринимательство и запускает двигатель роста - поточное создание и воспроизводство новых технологий, с последующей их коммерциализацией, в инклюзивной системе накопления и перераспределения новых знаний.

Покупка патентов участниками предполагает фиксированные затраты на вход в отрасль, имеющие инвестиционную природу, следовательно, и сроки окупаемости за счет будущих прибылей. В условиях свободного входа равновесная цена патента устанавливается на уровне приведенной стоимости потока монопольных прибылей. Следовательно, рынок инноваций нельзя считать рынком совершенной конкуренции, несмотря на созданные фундаментальные характеристики и рыночные стимулы. Свобода технологического предпринимательства сама по себе не обеспечивает оптимального распределения ресурсов между секторами. Как следствие, инновационная активность в силу монопольного положения производителей оказывается ниже оптимального уровня. По мнению Ромера, недостаточную эффективность рынка инноваций может исправить политика государства, включающая в себя субсидирование исследова- ний и разработок и регулирование в области патентного права.

Процессы монополизации интеллектуального капитала ошибочно рассматривать в отрыве от бизнеса высокотехнологичных компаний и операционной деятельности других фирм. Заметим, что монетизация новых технологий - как материализованный интеллектуальный капитал в товаре особого свойства - не всегда является главной целью компаний, или императивом государственной политики. Вовлечение новых знаний в хозяйственный оборот компании происходит неоднородно, поэтому интеграция в бизнес осуществляются по различным каналам и в разных вариациях, в зависимости от степени монополизации интеллектуального капитала:

- посредством собственного использования компанией новых знаний (своих разработок) и их интеллектуального воспроизводства (эффект масштабирования и тиражирования наработок, их непрерывное улучшение и продажа в режиме «черный ящик»);

- путем передачи права владения и использования собственного интеллектуального капитала третьим лицам (формат аренды), при сохранении права собственности (и права распоряжения соответственно);

- комбинированные сочетания купли-продажи новых знаний (материализованных в юридической “облочке” патентов, нематериальных активов, коммерческих прав и др.), и расщепление интеллектуального капитала на объект собственности (монопольное владение) и фактор производства (объект хозяйствования). 
Дуализм прав монополии на интеллектуальный капитал- как на объект собственности и как на объект хозяйствования, явственно проявляется, если модель монетизации имеет четкое разделение денежных потоков - от владения (рента), и от операционной деятельности (доход).Подобная амбивалентность предполагает рефлексивность монополии и конкуренции - их взаимное проникновение в динамическом процессе воспроизводства интеллектуального капитала, и создания добавленной стоимости товаров и услуг на его основе.

Как отмечал К. Маркс, монополия, как противоположность свободной конкуренции, не уничтожает ее, а меняет формы и обостряет конкурентную борьбу. “В практической жизни мы находим не только конкуренцию, монополию и их антагонизм, но также и их синтез, который есть не формула, а движение. Монополия производит конкуренцию, конкуренция производит монополию. Монополисты конкурируют между собой, конкуренты становятся монополистами.” (Маркс К., Энгельс Ф. Соч. 2-е изд. Т.4 С. 166).

Вернемся к модели Ромера, и рассмотрим как проявляется озвученный эффект в ее рамках. Так, продуктивность сектора 3 (Разработок) растет с увеличением накопленных знаний, при “жестком” условии сохранения на них патентного права (фактически монополии). Здесь мы видим наглядное проявление Марксового синтеза монополии и конкуренции в рамках динамического процесса:

1. Острая конкуренция на рынке идей, новых знаний, исследований и разработок (сектор 3) стимулирует производство промежуточного продукта (сектор 2), который монополизируется патентным правом (или техническими средствами) и защищает тем самым своего производителя.

2. В результате переход к созданному конечному продукту (сектор 1) предполагает конкуренцию нескольких “черных ящиков” (реализованных патентов), зашитых в однородных конечных продуктах, уже от различных производителей (борьба за потребителя и рынки сбыта).

3. Эта фаза конкуренции конечных продуктов между собой длится вплоть до полной победы одного продукта (технологии), с переходом в монополистический цикл - до появления новых товаров-заменителей или других воздействий, включая изменения фундаментальных характе- ристик экономики (предпочтений потребителей, технологических параметров, институциональных факторов).

Цикличность модели очевидна, и она имеет свою родовую особенность - каждая фаза цикла не столько сменяет другую в порядке очередности, сколько выступает внутренним генератором - воспроизводит новый цикл в условиях непрерывных изменений среды. Процессы абсолютно схожи с явлениями, описанными в теории рефлексивности на финансовых рынках (Дж. Сороса), когда взаимное проникновение ожиданий и активных действий участников (рыночных игроков) предопределяет движение биржевых котировок, в поисках динамического равновесия цены фондового актива. Неслучайно в развитых экономиках мира прослеживается устойчивая взаимосвязь развития технологических рынков и рынков капитала - это звенья одной цепи, в рамках сбалансированной финансово-экономической модели, интегрированной в институциональную “экосистему”. Базис системы образуют финансовый капитал и интеллектуальный, которые имеют взаимное проникновение, дополнение и степень влияния.

Финансовый капитал можно трактовать как ожидания и умозаключения внешних инвесторов о будущей стоимости Компании, основанные на денежных потоках и бизнес-показателях дня сегодняшнего.

Интеллектуальный капитал предполагает деление на Человеческий - инновационная составляющая, интеллектуальная собственность, и Структурный - включает капитал клиентский (потребительский), организационный, процессный, нематериальные активы (модели SkandiaValueScheme Л. Эвиссона).

Осмелимся предположить, что природное сходство финансовых и технологических рынков предопределяется монопольным правом на интеллектуальный капитал - это их экзистенция, фундаментальная основа развития.

Обращает на себя внимание уровень концентрации активов в банковском и инвестиционном секторе - степень их монополизации также достаточна высока. Во многих странах подавляющая часть активов приходится на пять-десять крупнейших банков:

По данным МВФ, в среднем по миру доля пяти крупнейших банков в активах банковской системы составляет $81 \%$, в среднем по странам ЕС - 91\%. Как правило, в более крупных странах 


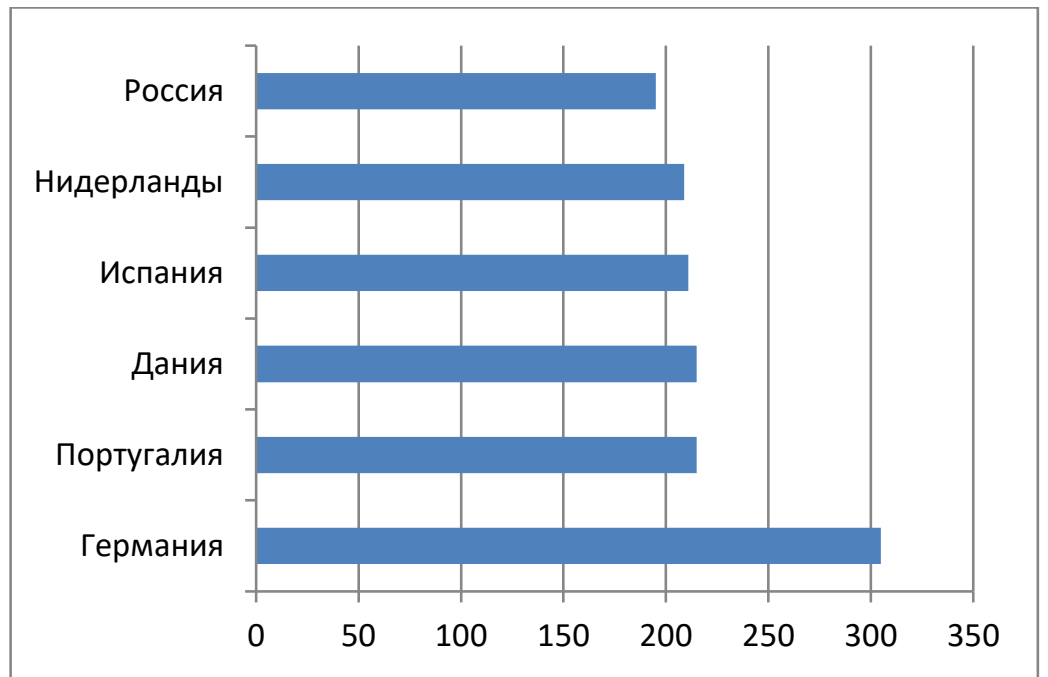

Puc. 3. Соотношение активов крупнейшего и второго по величине банка страны,\%

концентрация меньше, но и в самых больших странах ЕС этот показатель колеблется от 70 до 85\% (В России он составляет всего 56\%).

К слову, в динамике показателей банковского сектора РФ все больше приближается к типичной по структуре: доля ТОП-банков растет, а разрыв между крупнейшим банком и прочими банками сокращается. В большей степени отечественную банковскую систему, конечно, отличает доля государственного капитала в банковской системе.

Финансовые рынки, как принято считать в инвестиционном сообществе, «двигают» крупные игроки, которые задают и формируют тренды [5]. Равно как и технологические прорывы осуществляют технологические предприниматели, которые первыми успели запатентовать (монополизировать) прорывную технологию или область знаний, завершить цепочку научных открытий или коммерциализировать отдельное звено.

Если мы наложим данные явления на исторический процесс, и вспомним исследование Т. Пикетти о социальном неравенстве и концентрации капитала в руках узкого круга лиц последние столетия, то мы вновь увидим монополистическую природу инновационного развития. Ранее мы акцентировали внимание на ключевых закономерностях, выявленных Т. Пикетти (статья Ларионова А.В. “Взаимосвязь социального неравенства и человеческого капитала в XXI веке”):

- чем крупнее капитал, тем быстрее он растет - за годы финансовой глобализации среднегодовой рост капитала составлял около 4\%, при этом крупный капитал рос на 6-7\% (в 3-4 раза выше темпов роста мировой экономики), а мелкий на $-2-3 \%$ (это и есть базис социального неравенства);

- главной силой устранения социального неравенства выступают процесс распространения знаний и инвестиции в повышение квалификации и в образование;

• “Второй закон капитализма” (закон кумулятивного роста и кумулятивной доходности) гласит: даже незначительное превышение доходности капитала над уровнем роста экономики на протяжении длительного периода приводит к значительному росту капитала, а также мощным и дестабилизирующим воздействиям на структуру и динамику социального неравенства.

Также мы отмечали, что модель неравенства - это монополистическая формация крупного капитала, где имеет место сочетание высоких входных барьеров и масштабности (капиталоемкости). Предпринимательский талант, безусловно, мотор экономического и технологического развития, и представляет собой “человеческую” составляющую интеллектуального капитала по своей природе. В терминологии классической производственной функции, ИК также является фактором производства, и составной частью добавленной стоимости - ее “потребительской” компоненты, как продукт труда “сложного” и “конкретного” (по Марксу). Таким образом человеческий капитал - как элемент капитала интеллектуального - увеличивает капитал совокупный через добавленную стоимость, воспроизводит его, и обеспечивает 
прирост во времени.

Однако границы роста стоимости (как экономической категории) упираются в “ареал обитания” крупного капитала, который либо блокирует зачатки конкуренции (ресурсы позволяют), либо присовокупляет их к сфере своих интересов (через выкуп или экспроприацию). Получается, что монополизация есть социальное явление, а экономическое и технологическое развитие общества невозможно вне плоскости крупного капитала, или за периметром монопольного владения ресурсами и властью, в различных формах проявления этого владения.

В своем исследовании Т.Пикетти наглядно показал, что максима демократических обществ - равенство и ключевая роль талантов, навыков и усилий индивидуумов - не являются локомотивом экономики, темпы роста которой базируются исключительно на наследуемом богатстве и родственных связях, имеющих монополистическую идентичность. В модели эндогенного роста Ромера монополизм также является краеугольным камнем экономики знаний, и идентифицируется с присущим дуализмом ролей - выполняет как защитную функцию рынка инноваций, так и сдерживающую за счет входных барьеров. Ранее Ромер в своей работе «Рост на основе возрастающей отдачи благодаря специализации» (1987) отмечал, что нерегулируемый рынок может производить инновации, но они не будут оцениваться по достоинству. Решить эту проблему должно государство путем субсидий на научно-исследовательские разработки и развития патентной системы.

По мнению Ромера, свободный вход в сектор Промежуточного продукта (2) ведет к непрерывному увеличению разнообразия идей, которые не устаревают и в совокупности формируют капитал для сектора конечного продукта. Фактор разнообразия идей и технологий дает синергетический эффект общей факторной продуктивности для конечного продукта. Темпы долговременного роста за счет этого эффекта предполагаются значительно выше. Мы вновь вернулись к синтезу конкуренции и монополии, который, по словам Маркса, “есть не формула, а движение".

Тождество монополии и общественного развития действительно выглядит парадоксальным в “демократической” оболочке общества, которую принято считать правильной и прогрессивной. Однако это предмет другого исследования.

\section{Библиографический список}

1. Михайлов А.М., Пронина Е.Ю. Экономическая природа интеллектуального капитала и его взаимосвязь с человеческим капиталом //Вестник Самарского государственного экономического университета. 2013. № 5 (103). С. 87.

2. Кузьмина О.Ю., Коновалова М.Е. Особенности воспроизводства интеллектуального капитала // Вестник Самарского государственного экономического университета. 2015. № 10 (132). С. 6-14.

3. Ларионов А.В., Коновалова М.Е. Рефлексивность и ее роль в управлении стоимостью компании //Балтийский экономический журнал. 2017. № 1 (17). С. 16-22.

4. Ларионов А.В., Коновалова М.Е. Роль интеллектуального капитала в современном кризисе банковской системы РФ // Вестник Самарского государственного экономического университета. 2017. № 12 (158). С. 5-11.

5. Konovalova M., Kuzmina O., Mikhailov A., Hansevyarov R., Persteneva N. Intellectual capital as a key factor in the economic development of the region //Global Media Journal. 2016. T. 14. № 27. C. 39. 